Article

\title{
Effects of Predator-Prey Interactions on Predator Traits: Differentiation of Diets and Venoms of a Marine Snail
}

\author{
David A. Weese ${ }^{1, *}$ and Thomas F. Duda Jr. ${ }^{2,3, *(D)}$ \\ 1 Department of Biological and Environmental Sciences, Georgia College and State University, Milledgeville, \\ GA 31061, USA \\ 2 Department of Ecology and Evolutionary Biology and Museum of Zoology, University of Michigan, \\ Ann Arbor, MI 48109, USA \\ 3 Smithsonian Tropical Research Institute, Balboa, Ancon, Republic of Panama \\ * Correspondence: david.weese@gcsu.edu (D.A.W.); tfduda@umich.edu (T.F.D.J.)
}

Received: 24 April 2019; Accepted: 23 May 2019; Published: 25 May 2019

\begin{abstract}
Species interactions are fundamental ecological forces that can have significant impacts on the evolutionary trajectories of species. Nonetheless, the contribution of predator-prey interactions to genetic and phenotypic divergence remains largely unknown. Predatory marine snails of the family Conidae exhibit specializations for different prey items and intraspecific variation in prey utilization patterns at geographic scales. Because cone snails utilize venom to capture prey and venom peptides are direct gene products, it is feasible to examine the evolution of genes associated with changes in resource utilization. Here, we compared feeding ecologies and venom duct transcriptomes of individuals from three populations of Conus miliaris, a species that exhibits geographic variation in prey utilization and dietary breadth, in order to determine the extent to which dietary differences are correlated with differences in venom composition, and if expanded niche breadth is associated with increased variation in venom composition. While populations showed little to no overlap in resource utilization, taxonomic richness of prey was greatest at Easter Island. Changes in dietary breadth were associated with differences in expression patterns and increased genetic differentiation of toxin-related genes. The Easter Island population also exhibited greater diversity of toxin-related transcripts, but did not show increased variance in expression of these transcripts. These results imply that differences in dietary breadth contribute more to the structural and regulatory differentiation of venoms than differences in diet.
\end{abstract}

Keywords: conotoxin; RNA-seq; differential expression; single nucleotide polymorphism; predator-prey interactions

Key Contribution: This work reveals how structural and regulatory differences contribute to the differentiation of venoms among populations with different diets.

\section{Introduction}

Disjunct populations of widespread species are often exposed to varying environmental conditions that can lead to population differentiation and local adaptation. Indeed, geographic mosaics of interacting species may generate different selection regimes among populations [1] that can drive the genetic and phenotypic divergence of these populations and ultimately facilitate their reproductive isolation [2,3]. Traits that operate at the interface of species interactions (e.g., those directly associated with predator-prey interactions) represent some of the primary targets of selection among populations that differ in how they interact with other species and the identity and characteristics of these other 
species. For example, populations of male guppies exposed to different communities of predators differ in color intensity, a feature utilized by their visual predators [4]. Additionally, experimental populations of Brassica rapa plants diverge in floral traits in response to exposure to pollinators that are attracted by these traits [5]. Although such examples highlight the effect of species interactions on the evolution of traits linked to these interactions, the molecular mechanisms underlying many of these phenotypic changes are largely unknown.

Given that venoms are typically comprised of direct gene products that operate directly at the interface of predation [6], venomous organisms offer tractable systems for addressing questions concerning the evolution of genes associated with traits tightly linked to predator-prey interactions. Members of the marine gastropod family Conidae (cone snails) are a hyper-diverse group of over 800 species that utilize venom to capture prey [7]. Venoms of cone snails are largely comprised of small cysteine-rich peptides (conotoxins) [8] that exhibit considerable diversity among species [8-10]. Conotoxin genes are encoded by many large gene families [11] and evolve under positive selection [11,12]. In addition, high rates of gene gain and gene loss contribute to divergence in the composition of conotoxin gene families among species [13]. Differences in conotoxin gene expression patterns are also associated with interspecific differences in venom composition [10,12]. Together, these mechanisms (i.e., elevated rates of evolution, rapid gene turnover, and variation in expression patterns) contribute to the observed differences in toxin composition among cone snails (as described above) and other venomous species (e.g., snakes [14-16]).

Cone snails are trophic specialists that show strong interspecific differences in diet [17-24]. Given that members of the Conidae differ in prey utilization patterns, interspecific differences in venom composition presumably reflect the evolution of venoms for use on different prey. However, while the mechanisms responsible for the observed differences in venom composition among species (as discussed above) have been elucidated, which of these mechanisms contribute to the differentiation of venoms among populations of widespread species that differ in prey utilization patterns remains unknown.

Conus miliaris is a widely distributed cone snail inhabiting tropical and subtropical waters from the eastern shores of Africa in the Indian Ocean to Easter Island in the southern Pacific [25]. Throughout its range, $C$. miliaris co-occurs with up to 36 congeners [26] and is a prey specialist that primarily feeds on just a few species of eunicid polychaetes [25]. However, at Easter Island, where congeners are largely absent, $C$. miliaris has undergone ecological release and feeds on a much more diverse assemblage of prey, including additional species of eunicids and members of nine other polychaete families [25]. The expanded dietary breadth of $C$. miliaris at Easter Island offers an excellent opportunity to evaluate the impacts of different feeding ecologies on the evolution and differentiation of venoms and to identify the molecular mechanisms contributing to this differentiation.

Previous investigations of patterns of genetic differentiation of populations of C. miliaris in the Indo-West Pacific, based on analyses of sequences of regions of the mitochondrial cytochrome oxidase I gene and two O-superfamily conotoxin loci, illustrate that most populations exhibit low levels of genetic differentiation $[27,28]$. The inferred high levels of population connectivity are presumably achieved via high rates of gene flow accommodated by a planktonic larval phase that exists up to three weeks [29]. Nonetheless, the population at Easter Island is considerably genetically differentiated from other populations and levels of differentiation are greater for the conotoxin genes than for the mitochondrial locus, a pattern that was interpreted to reflect low levels of gene flow between populations at Easter Island and elsewhere in the Indo-West Pacific, and strong selection at conotoxin loci in response to dietary differences $[27,28]$.

To determine patterns of genetic variation and patterns of variation in gene expression among populations of $C$. miliaris, we characterized venom duct transcriptomes of individuals of this species from three locations in the Indo-West Pacific (Guam, American Samoa, and Easter Island). After assembling and annotating transcripts, we categorized transcripts into two classes: those that show homology to genes encoding peptides that are known venom components (toxin-related) and all other transcripts (non-toxin-related) that presumably represent mRNAs of "house-keeping" genes. We 
evaluated these transcript sets to determine if populations exhibit more differentiation at transcripts encoding venom components than at other transcripts. In addition, while past work has shown that the population at Easter Island has a wider dietary breadth than populations elsewhere, we characterized diets of individuals from these three locations using a DNA-based approach to enable quantitative measures of dietary breadth and differences in prey utilization among populations and to determine if individuals at Easter Island are specialists for particular prey species. Moreover, we present diet data for populations at Guam and American Samoa as these were previously unavailable. We specifically sought to determine how dietary differences are associated with structural and regulatory differentiation at toxin-related and non-toxin-related transcripts among populations. Although we assume that many of the transcripts encoding venom components are utilized in venoms for capturing prey, several recent studies have shown that some cone snail species utilize their venom to deter predation and that offensive venoms differ considerably from defensive ones [30,31]. Moreover, the three locations are likely to differ in biotic and abiotic characteristics that may present distinct challenges for the populations of $C$. miliaris at these sites. Hence, patterns of variation observed for transcriptomes may be due to other factors and not necessarily result from differences in diet.

\section{Results}

\subsection{Dietary Characterizations}

We obtained 170 16S-rDNA sequences from feces or regurgitated worms from individuals of C. miliaris from Guam, American Samoa, and Easter Island. These included 59 sequences from feces of 58 specimens of $C$. miliaris at Guam (including two sequences recovered from feces of one individual), 21 sequences from 21 specimens at American Samoa, and 90 sequences from 68 specimens at Easter Island (including two sequences recovered from regurgitated worms, two obtained from two prey items present in the feces of one individual, 38 from feces recovered from two feeding bouts of 19 individuals, and three from three feeding bouts of one individual) (GenBank accession numbers MH634087-MH634256). In gene trees, recovered sequences occurred in 15 tip clades that were interpreted to represent 15 species of polychaetes (Table 1, Supplementary Figure S1). Sequences in all clades except one (Eunicidae ' $X 8^{\prime}$ ) differed at only a few nucleotide sites. While only three and four prey species in the family Eunicidae were recovered from feces from individuals at Guam and American Samoa, respectively, sequences representing 10 species (nine species of eunicids (families Eunicidae, Onuphidae, and Lumbrineridae), one species of nereid and one capitellid species) were recovered from individuals at Easter Island. As indicated above, we examined fecal materials from separate feeding bouts for 20 individuals at Easter Island (two feeding bouts for 19 individuals and three feeding bouts for one individual). These prey items represented different species in all but five cases.

Only one prey item was shared among all populations (Eunicidae ' $\left.X 8^{\prime}\right)$. Although most individuals at American Samoa utilized this taxon $(\sim 60 \%)$, it was less frequently recovered at Guam $(\sim 8 \%$ of prey items consumed) and Easter Island $(\sim 2 \%)$. All other inferred prey species, including the most commonly detected prey species at Guam (Eunicidae ' $\mathrm{X} 6$ ', $\sim 67 \%$ ) and Easter Island (Palola A1, 38\%), were unique to single locations. Estimates of dietary overlap $\left(\mathrm{PS}_{\mathrm{I}}\right.$ values) among populations ranged from 0.023 to 0.083 and were less than all values calculated from resampled data (lowest value obtained was 0.354 ) (i.e., $P<10^{6}$ ). The Shannon diversity index calculated for the Easter Island population (1.77) was nearly twice as large as those for populations from American Samoa (0.93) and Guam (0.98) (Table 1). In addition, average Kimura 2-parameter distances among sequences of prey from Easter Island (0.321) were about two- to three-fold greater than those from American Samoa (0.161) and Guam (0.114) (Table 1). 
Table 1. Dietary data for individuals of C. miliaris from locations in the Indo-West Pacific (see Supplementary Figure S1).

\begin{tabular}{cccc}
\hline Prey Item/Statistic & Easter Island & Guam & American Samoa \\
\hline Eunicidae (total) & 76 & 59 & 21 \\
Eunicidae 'X6' & & 40 & 13 \\
Eunicidae 'X7' & 2 & 10 & \\
Eunicidae 'X8' & 13 & & \\
Eunicidae 'X9' & 5 & & \\
Eunicidae 'X10' & 19 & & 4 \\
Eunicidae 'X13' & 2 & & \\
Eunicidae 'X15' & & 5 & \\
Eunicidae 'X16' & 35 & & \\
Eunicidae 'X18' & & & \\
Palola A1 & 4 & & \\
Palola A3 & 1 & & \\
Onuphidae ('O1') & 8 & & \\
Lumbrinereidae ('L1') & 1 & 59 & 1 \\
Nereididae ('N2') & 90 & 4 & 0.93 \\
Capitellidae ('C1') & 10 & 1 & 0.161 \\
Number of prey items identified & 5 & 0.98 & \\
Inferred number of species & 1.77 & 0.114 & \\
Inferred number of families & 0.321 & & \\
Shannon diversity index of prey & & & \\
Average genetic distances among prey & & & \\
\hline
\end{tabular}

\subsection{Sequence Datasets, de novo Transcriptome Assembly and Transcript Annotation}

We generated 349,293,902 paired-end 200 bp reads from 22 C. miliaris individual cDNA libraries in a single flow cell lane averaging $15,876,996( \pm 2,052,016)$ reads per individual (Table 2). After digital normalization, 22,293,902 paired-end reads were assembled using the Trinity de novo assembler resulting in a reference transcriptome for C. miliaris of 204,951 transcripts. Despite being a known issue with short-read assemblies [32], the larger number of transcripts in our C. miliaris assembly is surprising given the number of genes recently described from molluscs such as Lottia giganeta (23,851; Lotgi v1.0) and Pinctada fucata (23,257 [33]). However, many of the transcripts were either not annotated or identified as non-metazoan, likely representing bacteria, fungi or unicellular eukaryotes (i.e., possible contaminants). Additionally, as this assembly represented a combination of individuals from genetically distinct populations (see below), the high number of transcripts may represent allelic variation or different regions of the same genes that are not overlapping or combined during assembly [32].

Table 2. Summary for the assembly and annotation of the C. miliaris, Easter Island, Guam, and American Samoa transcriptomes.

\begin{tabular}{ccccc}
\hline Statistic & C. miliaris & Easter Island & Guam & American Samoa \\
\hline Number of PE reads & $349,293,902$ & $131,525,916$ & $130,566,380$ & $87,201,606$ \\
Total transcripts & 204,951 & 149,583 & 134,741 & 98,828 \\
Average transcript length (bp) & 624.2 & 560.4 & 550.5 & 428.9 \\
Longest transcript (bp) & 25,902 & 23,251 & 16,001 & 15,460 \\
N50 (bp) & 879 & 719 & 693 & 463 \\
Annotated transcripts (\%) & $31,099(15.2)$ & $23,166(15.5)$ & $24,303(16.3)$ & $17,956(18.2)$ \\
Toxin-related transcripts & 516 & 435 & 340 & 284 \\
\% of total reads mapped to & 66 & 59 & 72 & 65 \\
toxin-related transcripts & & & &
\end{tabular}

For Easter Island, Guam, and American Samoa population transcriptomes, 131,525,916, 130,566,380, and $87,201,606$ paired-end reads were assembled into $149,583,134,741$, and 98,828 transcripts, receptively (Table 2). Given the smaller number of individuals included in the American Samoa population 
assembly (i.e., six as compared with eight in the Easter Island and Guam assemblies), the lower number of transcripts produced by this assembly is not surprising. However, when assemblies were conducted on an individual basis, the number of transcripts recovered for each of the 22 individuals was similar across populations (data not shown). Statistics (e.g., number of transcripts, average length of transcripts, N50, etc.) for each assembly are presented in Table 2.

The C. miliaris reference transcriptome as well as population transcriptomes were annotated using BLASTx searches against locally curated databases consisting of conotoxins, annotated proteins from Aplysia californica and Lottia gigantea genomes, known Conus proteins, as well as the UniProt protein database. Overall, 31,099 (i.e., $\sim 15 \%$ ) of the transcripts from the C. miliaris reference transcriptome had similarity $\left(<\right.$ E-values $\left.1 \times 10^{-5}\right)$ with known proteins or conotoxins in the reference databases (Table 2). Of these 31,099 annotated transcripts, 516 were identified as being toxin-related. For the population level assemblies, an average of 21,808 transcripts had similarity to proteins in our BLAST databases with 435, 340, and 284 transcripts being identified as being toxin-related in the Easter Island, Guam, and American Samoa assemblies, respectively (Table 2). When toxin-related transcripts are categorized into superfamilies, no obvious population level differences are seen (Figure 1). We evaluate whether or not populations exhibit differences in toxin transcript composition below the level of superfamilies through examination of patterns of expression as discussed below.

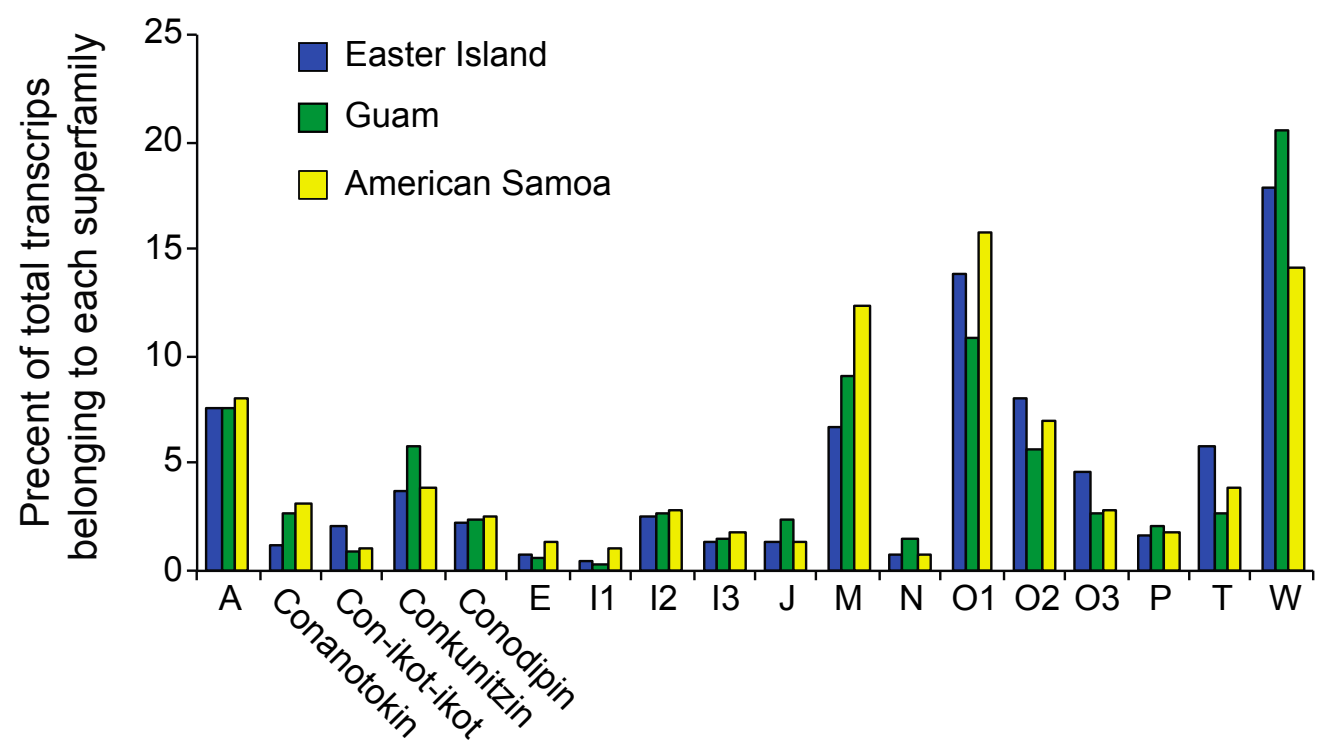

Predominant conotoxin superfamilies

Figure 1. The percentage of toxin-related transcripts recovered belonging to each of the major conotoxin superfamilies from populations of C. miliaris from Easter Island, Guam, and American Samoa. These transcripts make up 85, 81, and 86 percent of toxin-related transcripts recovered from Easter Island, Guam, and American Samoa, respectively.

\subsection{Differential Expression}

On average, approximately three million quality trimmed, single-end reads from each individual were successfully mapped to the annotated C. miliaris reference transcriptome. Of the 31,099 annotated C. miliaris transcripts, 4694 were found to be differentially expressed among individuals. Of the 30,543 annotated transcripts not related to toxins, 4187 were found to be differentially expressed. In both cases, hierarchical clustering failed to differentiate between populations. However, when only toxin-related transcripts were analyzed, 141 transcripts were differentially expressed among individuals. Furthermore, based on hierarchical clustering of the differentially expressed toxin-related transcripts, expression patterns of individuals at Easter Island were differentiated from those of individuals at Guam and American Samoa (Figure 2, Supplementary Tables S1 and S2). When we 
only considered individuals from Guam and American Samoa, eight transcripts were differentially expressed among individuals and hierarchical clustering did not separate individuals from the two locations (results not shown). We calculated the coefficients of variation (CV) of expression values of toxin-related transcripts of the three populations to determine if individuals from the Easter Island population show greater variation in expression levels than individuals from populations elsewhere. On the contrary, levels of variation were similar among the three populations; slightly more transcripts at Guam (157) showed higher CV values than at either Easter Island (155) or American Samoa (133).

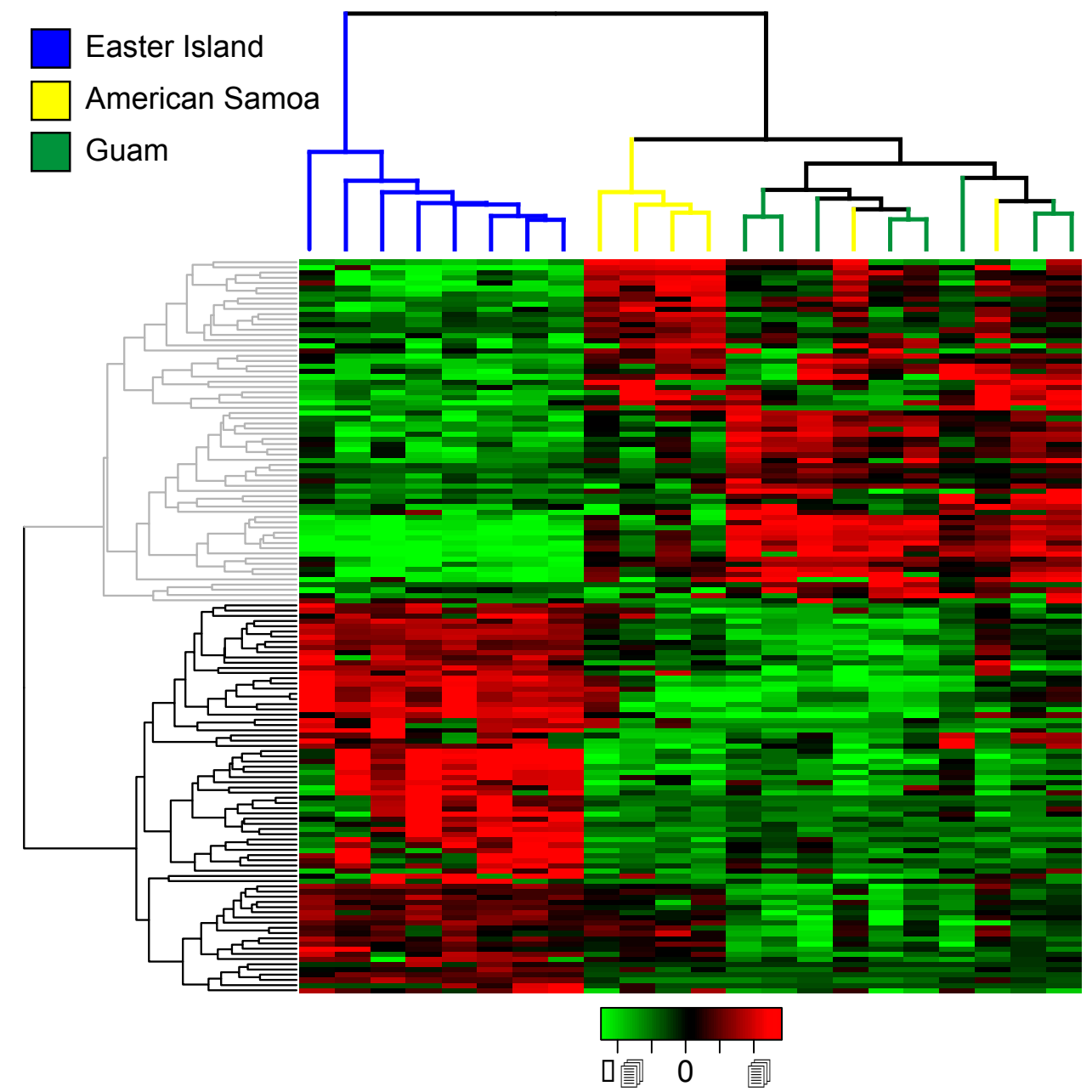

Figure 2. Heat map showing differences in toxin-related transcript expression between individuals of C. miliaris from Easter Island, Guam, and American Samoa based on replicate samples. Statistically significant differentially expressed transcripts were identified using edgeR at $P=0.001$, with a minimum four-fold difference in expression. Expression values (FPKM) are $\log _{2}$-transformed and median centered so that green represents under-expressed transcripts and red represents over-expressed transcripts. Unsupervised hierarchical clustering of the 22 C. miliaris individuals according to their transcript expression patterns is shown above the heat map. Similarly, unsupervised hierarchical clustering of transcripts with similar expression patterns is presented to left of heat map (Supplementary Tables S1 and S2).

\subsection{Single Nucleotide Polymorphisms, Diversity, and Population Structure}

The initial SNP screening identified 585,736 high-quality SNPs. Of these, 26,920 (i.e., 4.6\%) had confident genotypes for all 22 individuals. The multiplexing of 22 individuals in a single HiSeq lane likely accounts for the low percentage of confidently genotyped SNPs; the most highly expressed genes (e.g., conotoxins) were likely sequenced to a sufficient depth to be confidently genotyped for 
all individuals. Examination of the levels of diversity exhibited at these SNPs revealed that while non-toxin-related SNPs show similar levels of diversity among the three populations, the population at Easter Island shows greater transcript diversity at toxin-related SNPs than do the other populations (Table 3).

Table 3. Estimates of transcript diversity of populations of C. miliaris based on analyses of all $26,920 \mathrm{SNPs}$, 24,557 non-toxin related SNPs and 2363 toxin-related SNPs.

\begin{tabular}{cccc}
\hline Population & All SNPs & Non-Toxin-Related SNPs & Toxin-Related SNPs \\
\hline Easter Island & 0.159 & 0.155 & 0.198 \\
Guam & 0.153 & 0.153 & 0.149 \\
American Samoa & 0.157 & 0.157 & 0.155 \\
\hline
\end{tabular}

A principal component analysis of the 26,920 SNPs genotyped from all individuals suggests strong genetic differentiation between the Easter Island population and the Guam and American Samoa populations (Figure 3). Pairwise $\mathrm{F}_{\mathrm{ST}}$ values for all 26,920 SNPs were lower than, but comparable to those reported for the mitochondrial cytochrome oxidase I gene [27]. Values between Easter Island and Guam as well as Easter Island and American Samoa indicted higher genetic differentiation than between Guam and American Samoa (Table 4). Furthermore, while $\mathrm{F}_{\mathrm{ST}}$ values based on the 24,557 non-toxin-related SNPs indicated little genetic differentiation between populations, the 2363 toxin-related SNPs exhibited strong genetic differentiation, especially between the Easter Island population and the American Samoa and Guam populations (Table 5). Nonetheless, all pairwise comparisons revealed four-fold to five-fold greater differences in $\mathrm{F}_{\mathrm{ST}}$ values calculated for toxin-related SNPs than for non-toxin-related SNPs.

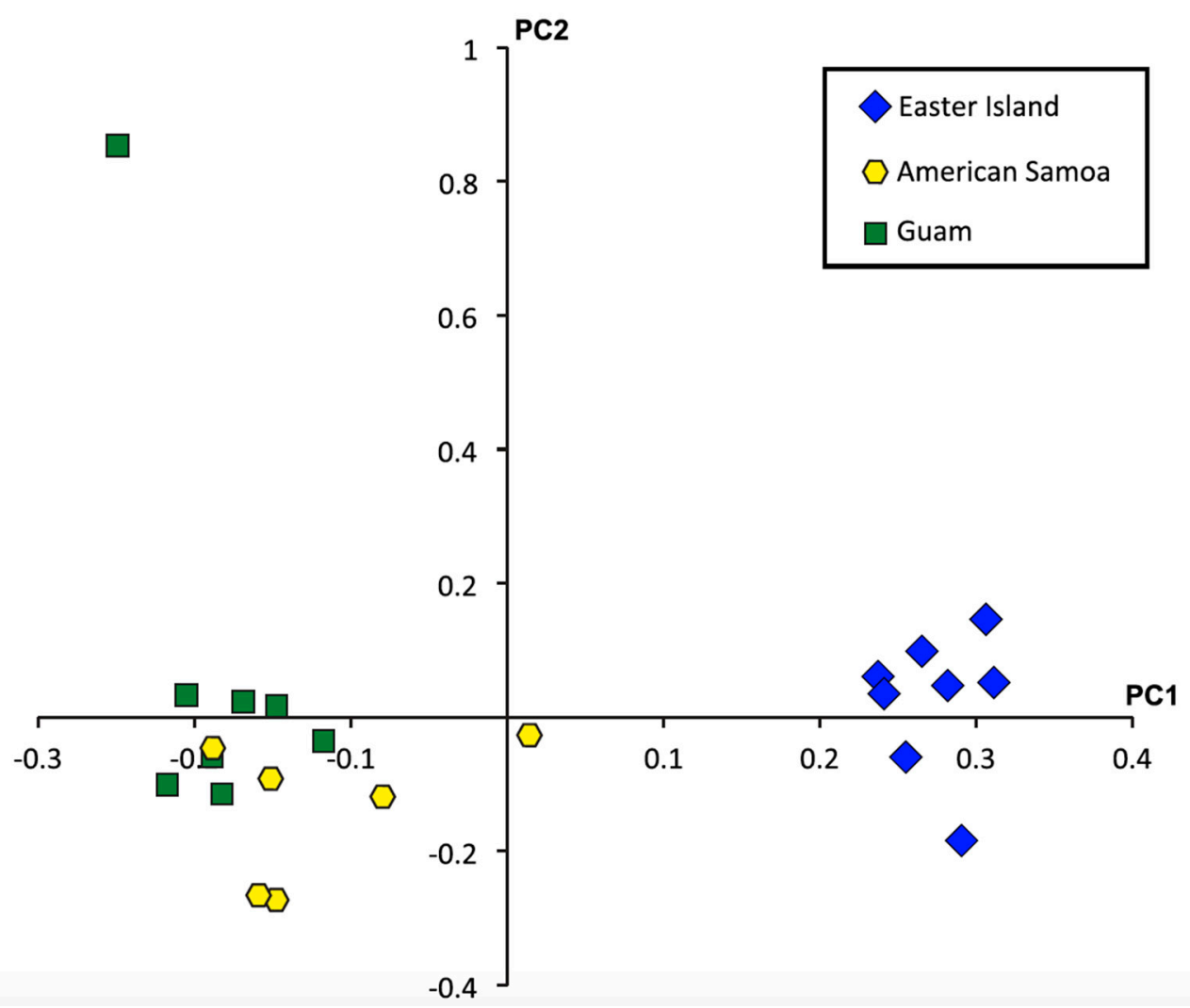

Figure 3. Principle components plot based on analyses of 26,920 single nucleotide polymorphisms (SNPs) with high quality genotypes for all 22 individuals. PC axis 1 is significant $\left(P=2.48 \times 10^{-15}\right)$. 
Table 4. Pairwise $\mathrm{F}_{\mathrm{ST}}$ values as measures of genetic differentiation between populations of $C$. miliaris based on analyses of mitochondrial cytochrome oxidase I sequences (above diagonal; from [27]) and all SNPs (below diagonal).

\begin{tabular}{cccc}
\hline Population & Easter Island & Guam & American Samoa \\
\hline Easter Island & - & 0.121 & 0.143 \\
Guam & 0.069 & - & -0.012 \\
American Samoa & 0.054 & 0.001 & - \\
\hline
\end{tabular}

Table 5. Pairwise $\mathrm{F}_{\mathrm{ST}}$ values as measures of genetic differentiation between populations of $C$. miliaris based on 24,557 non-toxin-related SNPs (above diagonal) and 2363 toxin-related SNPs (below diagonal).

\begin{tabular}{cccc}
\hline Population & Easter Island & Guam & American Samoa \\
\hline Easter Island & - & 0.050 & 0.034 \\
Guam & 0.207 & - & 0.008 \\
American Samoa & 0.178 & 0.035 & - \\
\hline
\end{tabular}

\subsection{Data Accessibility}

Raw NGS sequence data for each individual are available from NCBI SRA under accession numbers PRJNA257931 and SRP045405. Assembled transcripts are available from Dryad for C. miliaris as a whole, as well as for each geographic population, as FASTA files under accession number: 10.5061/dryad.t74q4. Relative expression levels are available from Dryad as tab-delimited files corresponding to the number of reads mapping back to each annotated transcript of the $C$. miliaris assembly and FPKM values for each of the 22 individuals, geographic populations, as well as for $C$. miliaris under accession doi: 10.5061/dryad.t74q4. Putative single nucleotide polymorphisms (SNPs) are available from Dryad as a VCF file under accession number: 10.5061/dryad.t74q4.

\section{Discussion}

Populations of C. miliaris exhibit substantial differences in diets in terms of the particular species preyed upon and dietary breadth at different locations (Table 1, Supplementary Figure S1). However, while resource use at Easter Island has expanded, individuals at Easter Island do not appear to show specializations for particular prey taxa. Although the wider dietary breadth at Easter Island is not associated with an increased diversity of venom components expressed (Table 2, Figure 1), this population exhibits a higher level of genetic variation at toxin-related genes than those from Guam and American Samoa (Table 3). Additionally, venom composition, in terms of gene expression patterns and levels of structural divergence, is most strongly differentiated at Easter Island (Table 5, Figure 2). Finally, while populations at Guam and American Samoa exhibit similar dietary breadths but otherwise largely prey on different polychaete species, toxin-related transcripts show a greater degree of differentiation than do other annotated transcripts (Tables 3 and 5). However, these populations do not exhibit differences in expression patterns of toxin-related transcripts (Figure 2). The significance and implications of these results are discussed below.

\subsection{Diets and Dietary Breadth}

Populations of C. miliaris at Guam, American Samoa, and Easter Island show little overlap in prey utilization and, as anticipated from Kohn's earlier work on the diets of this species [25], the population at Easter Island has a wider dietary breadth than populations at other locations where members of the polychaete family Eunicidae are the predominant prey type (Table 1, Supplementary Figure S1). Because we identified more prey items from individuals at Easter Island $(\mathrm{N}=90)$ than at Guam $(N=59)$ or American Samoa $(N=21)$, differences in the number of prey species identified may reflect the sample sizes used. Nonetheless, although the sample size for the population at Guam is 
nearly three times larger than that at American Samoa, dietary diversity statistics are comparable for these populations.

Populations with wide niche breadths, such as the population of C. miliaris at Easter Island, typically consist of (i) generalist individuals with similarly broad niche breadths (i.e., population and individual niche widths are similar), (ii) sets of specialist individuals that each utilize a subset of available resources (i.e., niche widths of individuals are non-overlapping and narrower than the population's niche width), or (iii) sets of generalist and specialist individuals that differ in niche width (i.e., niche widths of some individuals are nested within the niche widths of others) [34-37]. As multiple taxa were identified from fecal materials recovered for separate feeding bouts of several C. miliaris individuals (Table 1, Supplementary Figure S1), individuals at Easter Island do not appear to exhibit specializations for particular prey. Unfortunately, an insufficient number of observations was obtained to determine the level of dietary specializations of individuals. Because species diversity and population densities of polychaetes at Easter Island are comparable to those at other locations in the Indo-West Pacific [38], differences in dietary breadth are not likely to be due to differences in the density or diversity of available prey at the locations examined, but instead may be due to ecological release at Easter Island [25].

The feeding ecologies of the three populations examined are all distinct with very little overlap in resource use (Table 1, Supplementary Figure S1). While individuals at Easter Island prey on eunicid, onuphid, lumbrinerid, nereidid, and capitellid polychaetes, the diets of individuals at Guam and American Samoa consist solely of eunicids (Table 1, Supplementary Figure S1). Given this, it is not surprising that measures of dietary breadth at Guam and American Samoa are less than those for the population at Easter Island. These patterns of variation provide a framework to understand how differences in feeding specialization (as exhibited by all populations) and differences in dietary breadth (as exhibited by the population at Easter Island in comparison with populations at Guam and American Samoa) are associated with regulatory and structural changes among venom genes utilized to capture prey.

\subsection{Mechanisms Contributing to the Differentiation of Venoms among Populations with Different Resource Use Patterns}

Previous analyses of patterns of variation exhibited at two polymorphic conotoxin loci revealed significant differences in allelic frequencies at Easter Island, while populations at Guam and American Samoa showed no evidence of differentiation [28]. In addition, a phylogeographic study of $C$. miliaris based on an analysis of mitochondrial cytochrome oxidase I sequences suggested that the population at Easter Island is genetically isolated from populations elsewhere in the Indo-West Pacific and that other populations in this region were not genetically structured [27]. A much more expanded survey of genetic variation exhibited by the entire venom duct transcriptomes reveals similar trends (Tables 4 and 5 and Figure 3). Indeed, the population at Easter Island is the one that is most strongly differentiated at both toxin and non-toxin-related transcripts from other populations. Nonetheless, while the previous study of the two conotoxin loci showed no differentiation among populations at Guam and American Samoa, our results reveal that toxin-related transcripts show greater levels of divergence than non-toxin-related transcripts at these populations (Table 5). Given this, the differences in diet observed for these populations may drive divergence at toxin encoding genes through selection for effective capture of different prey types, although other explanations could be feasible. For instance, although cone snails utilize venoms to subdue and capture prey, venoms also serve a defensive role in some species $[30,31]$. Although we do not know if $C$. miliaris utilizes its venom defensively nor how predation pressures on this species differ among locations, it is possible that these or other factors are responsible for the patterns of variation that we observed. Future studies aimed at understanding patterns of variation in predation pressures and identifying defensive and offensive components of venoms of $C$. miliaris would help to address this issue. 
Populations with expanded niche breadths are proposed to exhibit greater phenotypic variation than populations with narrow niche breadths when individuals exhibit specializations for subsets of resources [34,36,39-41]. Here, we can specifically compare intraspecific patterns of genetic variation of genes associated with resource use for populations with different niche breadths. Across phylogenetically disparate cone snail species, there is a positive relationship between venom composition complexity and dietary breadth [42]. Within species however, wider dietary breadth does not appear to be associated with any large shifts in the major types of venom components expressed (Figure 1). Nonetheless, our family-level assignment of toxin types may obscure shifts in expression within these families. Indeed, individuals at Easter Island share more similar patterns of expression of toxin-related genes than do individuals from Guam and American Samoa based on estimates of coefficients of variation of toxin-related transcript expression values (see also Figure 2). On the other hand, the population at Easter Island exhibits greater transcript diversity at toxin-related transcripts than populations at Guam and American Samoa, while measures of diversity at non-toxin-related transcripts are comparable among the three populations (Table 3). These results align with a number of studies revealing a strong correlation between dietary breadth and conotoxin gene diversity [42-45]. Although we cannot attribute these patterns to the evolution of individual-level feeding specializations at Easter Island, they at least demonstrate that changes in feeding breadth are associated with structural changes at toxin-related genes.

The population of C. miliaris at Easter Island is distinct from other populations in terms of structural and regulatory divergence of toxin-related transcripts as well as its wider dietary breadth and lack of genetic connectivity with other populations in the Indo-West Pacific. Populations at Guam and American Samoa differ in diet, but have similar dietary breadths, show similar toxin-related transcript expression patterns, and apparently experience high levels of gene flow with each other. Although populations at Guam and American Samoa show greater differentiation at toxin-related than at non-toxin-related transcripts, the level of differentiation is much less than found for comparisons involving Easter Island. Differences in diet are associated with the genetic differentiation of conotoxin loci among the three population comparisons. Nonetheless, the extent of this differentiation is greatest when populations show large differences in dietary breadth and low levels of genetic connectivity. Because populations at Guam and American Samoa show similar conotoxin gene expression patterns despite large differences in diet, differences in conotoxin expression patterns appear to only be associated with differences in dietary breadth and lack of genetic connectivity of populations (i.e., at Easter Island), but not differences in diet. A similar association between the extent of differentiation of conotoxin genes and dietary breadth was also observed for C. ebraeus, another worm-eating species that exhibits geographical variation in feeding ecology [44]. Given these observations (i.e., differences in diet are associated with differentiation at toxin-related transcripts but not always associated with differences in expression patterns), changes in allelic frequencies and not changes in gene expression patterns may be responsible for divergence in venom composition among populations of cone snails that show differences in diet. Large changes in gene expression patterns may occur with shifts in dietary breadth, especially for shifts that involve an increase in the phylogenetic disparity of prey, or when populations are genetically isolated (i.e., gene flow with other populations is low). Given that we cannot disentangle how diets, dietary breadth, and gene flow are associated with mechanisms that facilitate or limit opportunities for the differentiation of venoms, future studies should explore patterns of variation of venoms among populations with different dietary breadths and high levels of gene flow, and with similar dietary breadths and low levels of gene flow.

\section{Conclusions}

To elucidate the contributions of predator-prey interactions to intraspecific genetic and phenotypic divergence, we characterized diets and applied a comparative transcriptomic approach to three populations of the cone snail C. miliaris. While the three populations showed very little overlap in prey utilization, the population at Easter Island exhibited a much broader dietary breadth than populations 
at American Samoa and Guam. Contrary to previous studies, no associations between particular conotoxin gene superfamilies or total conotoxin diversity and prey type were observed, supporting the hypothesis that differences in prey do not correlate to changes in gene superfamily size or total conotoxin diversity $[43,44]$. However, differentiation of conotoxin genes and changes in their expression patterns appear to be associated with differences in prey utilization and dietary breadths of populations. Such differentiation may be indicative of directional selection as a consequence of ecological pressures (i.e., dietary breadth) [46,47], a phenomenon that has been suggested to be important in early stages of divergence among populations $[48,49]$.

\section{Materials and Methods}

\subsection{Dietary Analyses}

Specimens of C. miliaris were collected at locations in Guam, American Samoa, and Easter Island and placed in small containers with seawater within one to two hours after collection. Fecal or regurgitated materials were recovered and preserved in 95\% ethanol. A mark-recapture study was performed at Easter Island, allowing for the recovery of feces from multiple feeding bouts from a subset of individuals. Feces were examined via microscopy to guide the DNA-based prey determinations. In particular, presence of multiple pairs of jaws, jaw parts, and either types of setae or acicula were used to infer the number of prey taxa present in feces. Worm fragments or small sections of regurgitated worms were removed from feces (one fragment from feces that appeared to contain a single prey item and multiple fragments (up to five) for feces that appeared to contain more than one prey item) and used for genetic identification.

Total genomic DNA was extracted from collected material using the EZNA Mollusc DNA extraction kit (Omega Bio-tek, Norcross, USA) following the manufacturer's recommendations. A combination of previously reported annelid specific primers (forward primers 16SANNf2 and 16SANNf3, reverse primer 16Spr1 [50]), a newly designed annelid specific forward primer (16SANNf4: GATATTTTAACCGTGCTAAGGTAGCG) and universal 16S primers (16Sar and 16Sbr [51]) were utilized to amplify an $\sim 300-350$ bp region of the mitochondrial large ribosomal subunit (16S-rDNA) gene. Reactions were conducted in $10 \mathrm{ul}$ reactions under the following conditions: 40 cycles of $94^{\circ} \mathrm{C}$ for $30 \mathrm{~s}, 60^{\circ} \mathrm{C}$ for $30 \mathrm{~s}$ and $72{ }^{\circ} \mathrm{C}$ for $30 \mathrm{~s}$.

Successfully amplified products were diluted 1:5 in deionized water and submitted for sequencing at the University of Michigan DNA Sequencing Core facilities. Ambiguities in chromatograms were corrected by comparison with the complementary DNA strand in Sequencher v5.0 (Gene Codes Corporation, Ann Arbor, USA). Sequences were manually aligned using Se-Al v2.0a11 [52] with several hundred annelid sequences obtained from GenBank. To delimit polychaete prey species, neighbor-joining trees were constructed under an appropriate model of evolution and 500 bootstrap replicates using MEGA v5.2.1 [53]. Given the difficulties of aligning 16S-rDNA sequences across major polychaete taxonomic categories, subsets of data for each major taxon were analyzed separately with tip clades of sequences inferred to represent distinct polychaete species.

Levels of dietary overlap among populations were evaluated by estimating proportional similarity indices (PS I values [54]) from species utilization frequencies. Statistical significance of similarity indices was evaluated using a Monte Carlo simulation approach with one million resampled datasets. Levels of prey diversity of each population were measured using Shannon diversity indices [55] and average genetic distances among sequences of prey as a proxy for the phylogenetic disparity of prey. We evaluated levels of resource specialization of individuals at Easter Island based on comparisons of prey items taken during separate feeding bouts.

\subsection{De novo Transcriptome Assembly and Annotation}

Detailed descriptions of sample collection, library preparation and sequencing, as well as transcriptome assembly and annotation are described previously in Genomic Resources Development 
Consortium [34]. Briefly, eight, eight, and six individuals of C. miliaris were collected from Easter Island, Guam, and American Samoa, respectively. Total RNA was extracted from 22 dissected venom ducts and prepared for sequencing in a single flowcell lane on an Illumina HiSeq 2000 at the University of Michigan DNA Sequencing Core.

Quality scores, nucleotide distributions, and the overall quality of the $100 \mathrm{bp}$ paired-end reads were examined using the FASTX Toolkit [56]. Given the high quality of the data and the fact that over-aggressive quality trimming can negatively affect the assembly of RNA-seq data [57] (D.A. Weese personal observation), the reads were not filtered or quality-trimmed prior to assembly. For the $C$. miliaris reference transcriptome, reads from all 22 individuals were combined and digitally normalized [58] prior to assembly using Trinity (version Trinityrnaseq_r20140413p1) [59]. For the individual location assemblies, raw reads were pooled based on sampling location (i.e., Easter Island, Guam or American Samoa) and assembled using Trinity under default parameters.

To annotate the de novo assemblies for each dataset (whole species and three geographic populations), transcripts were first searched against a locally curated databases of non-redundant conotoxin and conotoxin signal sequences downloaded from the Conoserver database [60] using BLASTx (version 2.2.29) with default parameters and retaining matches with an $e$-value $<10^{-5}$. Transcripts that failed to match any toxins in our conotoxin database were then compared to local databases comprised of: (1) annotated proteins from the two mollusc species available on the NCBI Unigene database, Aplysia californica, and Lottia gigantea; (2) all Conus related proteins downloaded from NCBI's nr database; and (3) the UniProt protein database using BLASTx with an $e$-value cut off of $1 \times 10^{-5}$. The assemblies were then divided into two sets: transcripts that were toxin-related, which are those transcripts that had homology with proteins in our conotoxin database and those that were annotated but had no homology to proteins in our conotoxin database (i.e., not toxin-related). Toxin-related transcripts were assigned to superfamilies based on their best hits in the BLASTx search against the conotoxin database.

\subsection{Differential Expression}

Annotated transcripts from the reference C. miliaris assembly were used as the reference transcriptome for the evaluation of expression values and SNP detection. Prior to mapping, reads were quality trimmed based on a phred-scale quality score cut-off of 20 with reads shorter than 20 bases being discarded using the FASTX Toolkit. Trimmed, single-end reads for each individual were then individually mapped against the reference transcriptome with Bowtie v1.0.1 [61] using the parameters -all -best -strata -m 300 -chunkmbs 512. On the basis of these alignments, RSEM v1.2.9 [62] was used with default parameters to estimate the expression level of annotated transcripts. Differential expression analyses were conducted on three subsets of the data: (1) all C. miliaris annotated transcripts, (2) C. miliaris transcripts not related to toxins, and (3) toxin-related C. miliaris transcripts following the methods outlined by Hass et al. [63]. For each population, individuals were treated as biological replicates and expression values were normalized by the trimmed mean of $M$ values (TMM) method using edgeR [64]. The differential expression values were calculated using the empirical Bayes estimation approach using the edgeR package [65] in Bioconductor (http://bioconductor.org). For visualization, transcripts that showed more than fourfold differences in expression with a false discovery-corrected statistical significance of $<0.001$ were hierarchically clustered using the heatmaps2 package in $R$. To evaluate patterns of variation in expression of toxin-related transcripts of the three populations, we calculated the coefficients of variation of expression values and determined if more loci show higher coefficients of variation at Easter Island than do the other populations.

\subsection{Single-Nucleotide Polymorphism (SNP) Identification, Diversity, Population Structure, and Outlier Analysis}

For SNP detection, trimmed paired-end reads for each individual were mapped to the $C$. miliaris reference transcriptome using Bowtie2 v2.1.0 [66] with the following parameters: -no-unal -local -p 6. 
After the duplicate reads in the alignments were marked with the MarkDuplicates utility of Picard [67], SNPs were identified using the Genome Analysis Toolkit [68,69] following the recommendations of the Broad Institute's best practices [70].

A principal component analysis (PCA) was conducted on high quality SNPs $(Q>20)$ using the EignSoft package [71] to investigate the population structure between individuals. The SNP dataset was further trimmed to exclude any variant sites that were genotyped heterozygous for all individuals (likely due to paralogous genes or contamination [32]) and any site in which the minor allele frequency was less than $2 \%$. Measures of transcript diversity (Qinter) and pairwise F $_{\mathrm{ST}}$ values for all SNPs, non-toxin-related SNPs, and toxin-related SNPs were calculated in GenePop [72].

Supplementary Materials: The following are available online at http://www.mdpi.com/2072-6651/11/5/299/s1. Figure S1: Neighbor-joining trees constructed with Kimura 2-parameter distances (Kimura 1980) from alignments of sequences recovered from feces or regurgitated worms (bold typeface) from Guam (G), American Samoa (AS), and Easter Island (EI) and polychaete sequences from GenBank (regular typeface; accession numbers included in names), Table S1: Differentially expressed toxin-related transcripts showing similar expression patterns of up-regulation in individuals of C. miliaris from Guam and American Samoa and down-regulation for individual from Easter Island, Table S2: Differentially expressed toxin-related transcripts showing similar expression patterns of up-regulation in individuals of C. miliaris from Easter Island and down-regulation from individual from Guam and American Samoa.

Author Contributions: T.F.D.J. designed the study and performed field sample collections; D.A.W. and T.F.D.J. performed lab work, analyzed data and drafted manuscript; conceptualization, T.F.D.J.; methodology, D.A.W. and T.F.D.J.; software, D.A.W. and T.F.D.J.; validation, D.A.W. and T.F.D.J.; formal analysis, D.A.W. and T.F.D.J.; investigation, D.A.W. and T.F.D.J.; resources, T.F.D.J.; data curation, D.A.W. and T.F.D.J.; writing-original draft preparation, D.A.W. and T.F.D.J.; writing-review and editing, D.A.W. and T.F.D.J.; visualization, D.A.W. and T.F.D.J.; supervision, D.A.W. and T.F.D.J.; project administration, D.A.W. and T.F.D.J.; funding acquisition, T.F.D.J.

Funding: Funding from the National Geographic Committee for Research and Exploration (CRE 8228-07), U.S. National Science Foundation (IOS 0718370), and an Associate Professor Support Funds award from the University of Michigan College of Literature, Science and the Arts supported the work.

Acknowledgments: Permits for sample collection at Easter Island were obtained from the Unidad de Recursos Bentónicos of the Subsecretaría de Pesca of Chile with the assistance of Javier Rivera Vergara, Brian Dyer, and Liliana Cortés Ortiz. Dan Chang assisted with fieldwork at Easter Island. Barry Smith, Alex Kerr, Jason Biggs, and others at the University of Guam Marine Lab coordinated field work in Guam. University of Guam students Marielle Terbio, Chris Rosario, Cabrinie Rivera, and Jonathan Lim provided lab and field assistance. Marlowe G. Sabater, Doug Fenner, and Lucy Jacob from the Department of Marine and Wildlife Resources and Seeseei. Toa, Sione Lam Yuen, Joe Atafua, and Monica Lui from the American Samoa Community College facilitated or assisted field studies in American Samoa.

Conflicts of Interest: The authors declare no conflict of interest. The funders had no role in the design of the study; in the collection, analyses, or interpretation of data; in the writing of the manuscript; or in the decision to publish the results.

\section{References}

1. Thompson, J.N. The Geographic Mosaic of Coevolution; University of Chicago: Chicago, IL, USA, 2005; ISBN 978-0-226-79762-5.

2. Schluter, D. Evidence for ecological speciation and its alternative. Science 2009, 323, 737-741. [CrossRef] [PubMed]

3. Thompson, J.N. The coevolving web of life. Am. Nat. 2009, 173, 125-140. [CrossRef]

4. Endler, J.A. A predator's view of animal color patterns. Evol. Biol. 1978, 11, 319-364.

5. Gervasi, D.D.L.; Schiestl, F.P. Real-time divergent evolution in plants driven by pollinators. Nat. Commun. 2017, 8, 14691. [CrossRef] [PubMed]

6. Casewell, N.R.; Wüster, W.; Vonk, F.J.; Harrison, R.A.; Fry, B.G. Complex cocktails: The evolutionary novelty of venoms. Trends Ecol. Evol. 2013, 28, 219-229. [CrossRef] [PubMed]

7. Puillandre, N.; Duda, T.F.; Meyer, C.; Olivera, B.M.; Bouchet, P. One, four or 100 genera? A new classification of the cone snails. J. Molluscan Stud. 2015, 81, 1-23. [CrossRef]

8. Olivera, B.M. Conus venom peptides: Reflections from the biology of clades and species. Annu. Rev. Ecol. Syst. 2002, 33, 25-47. [CrossRef] 
9. Duda, T.F., Jr. Differentiation of venoms of predatory marine gastropods: Divergence of orthologous toxin genes of closely related Conus species with different dietary specializations. J. Mol. Evol. 2008, 67, 315-321. [CrossRef]

10. Duda, T.F., Jr.; Remigio, E.A. Variation and evolution of toxin gene expression patterns of six closely related venomous marine snails. Mol. Ecol. 2008, 17, 3018-3032. [CrossRef] [PubMed]

11. Duda, T.F., Jr.; Palumbi, S.R. Molecular genetics of ecological diversification: Duplication and rapid evolution of toxin genes of the venomous gastropod Conus. Proc. Natl. Acad. Sci. USA 1999, 96, 6820-6823. [CrossRef]

12. Chang, D.; Duda, T.F., Jr. Application of community phylogenetic approaches to understand gene expression: Differential exploration of venom gene space in predatory marine gastropods. BMC Evol. Biol. 2014, 14, 123. [CrossRef] [PubMed]

13. Chang, D.; Duda, T.F., Jr. Extensive and continuous duplication facilitates rapid evolution and diversification of gene families. Mol. Biol. Evol. 2012, 29, 2019-2029. [CrossRef] [PubMed]

14. Gibbs, H.L.; Rossiter, W. Rapid evolution by positive selection and gene gain and loss: PLA2 venom genes in closely related Sistrurus rattlesnakes with divergent diets. J. Mol. Evol. 2008, 66, 151-166. [CrossRef]

15. Rokyta, D.R.; Wray, K.P.; Margres, M.J. The genesis of an exceptionally lethal venom in the timber rattlesnake (Crotalus horridus) revealed through comparative venom-gland transcriptomics. BMC Genom. 2013, 14, 394. [CrossRef] [PubMed]

16. Dowell, N.L.; Giorgianni, M.W.; Kassner, V.A.; Selegue, J.E.; Sanchez, E.E.; Carroll, S.B. The deep origin and recent loss of venom toxin genes in rattlesnakes. Curr. Biol. 2016, 26, 2434-2445. [CrossRef]

17. Kohn, A.J. The Ecology of Conus in Hawaii. Ecol. Monogr. 1959, 29, 47-90. [CrossRef]

18. Kohn, A.J. Food Specialization in Conus in Hawaii and California. Ecology 1966, 47, 1041-1043. [CrossRef]

19. Kohn, A.J. Abundance, diversity and resource use in an assemblage of Conus species in Enewetak Lagoon. Pac. Sci. 1980, 34, 359-369.

20. Marsh, H. Observations on the food and feeding of some vermivorous Conus on the Great Barrier Reef. Veliger 1971, 14, 45-53.

21. Kohn, A.J.; Nybakken, J.W. Ecology of Conus on eastern Indian Ocean fringing reefs: Diversity of species and resource utilization. Mar. Biol. 1975, 29, 211-234. [CrossRef]

22. Leviten, P.J. The foraging strategy of vermivorous conid gastropods. Ecol. Monogr. 1976, 46, 157-178. [CrossRef]

23. Reichelt, R.E.; Kohn, A.J. Feeding and distribution of predatory gastropods on some Great Barrier Reef platforms. In Proceedings of the Fifth International Coral Reef Congress, Tahiti, France, 27 May-1 June 1985; Volume 5, pp. 191-196.

24. Kohn, A.J.; Almasi, K.N. Comparative ecology of a biographically heterogeneous Conus assemblage. In Proceedings of the Fifth International Marine Biological Workshop: The Marine Flora and Fauna of Rottnest Island, Western Australia; Wells, F.E., Walker, D.I., Kirkman, H., Lethbridge, R., Eds.; Western Australia Museum: Pertha, Australia, 1993; pp. 509-521.

25. Kohn, A.J. Ecological shift and release in an isolated population: Conus miliaris at Easter Island. Ecol. Monogr. 1978, 48, 323-336. [CrossRef]

26. Kohn, A.J. Maximal species richness in Conus: Diversity, diet and habitat on reefs of northeast Papua New Guinea. Coral Reefs 2001, 20, 25-38.

27. Duda, T.F., Jr.; Lee, T. Isolation and population divergence of a widespread Indo-West Pacific marine gastropod at Easter Island. Mar. Biol. 2009, 156, 1193-1202. [CrossRef]

28. Duda, T.F., Jr.; Lee, T. Ecological release and venom evolution of a predatory marine snail at Easter Island. PLoS ONE 2009, 4, e5558. [CrossRef] [PubMed]

29. Kohn, A.J.; Perron, F.E. Life History and Biogeography: Patterns in Conus; Clarendon Press: Oxford, UK, 1994; ISBN 978-0-19-854080-9.

30. Dutertre, S.; Jin, A.-H.; Vetter, I.; Hamilton, B.; Sunagar, K.; Lavergne, V.; Dutertre, V.; Fry, B.G.; Antunes, A.; Venter, D.J.; et al. Evolution of separate predation- and defence-evoked venoms in carnivorous cone snails. Nat. Commun. 2014, 5, 3521. [CrossRef] [PubMed]

31. Prashanth, J.R.; Dutertre, S.; Lewis, R.J. Revising the Role of Defense and Predation in Cone Snail Venom Evolution. In Evolution of Venomous Animals and Their Toxins; Malhotra, A., Ed.; Springer: Dordrecht, The Netherlands, 2017; pp. 105-123, ISBN 978-94-007-6457-6. 
32. De Wit, P.; Palumbi, S.R. Transcriptome-wide polymorphisms of red abalone (Haliotis rufescens) reveal patterns of gene flow and local adaptation. Mol. Ecol. 2013, 22, 2884-2897. [CrossRef]

33. Takeuchi, T.; Kawashima, T.; Koyanagi, R.; Gyoja, F.; Tanaka, M.; Ikuta, T.; Shoguchi, E.; Fujiwara, M.; Shinzato, C.; Hisata, K.; et al. Draft genome of the pearl oyster Pinctada fucata: A platform for understanding bivalve biology. DNA Res. 2012, 19, 117-130. [CrossRef]

34. Bolnick, D.I.; Svanbäck, R.; Fordyce, J.A.; Yang, L.H.; Davis, J.M.; Hulsey, C.D.; Forister, M.L. The ecology of individuals: Incidence and implications of individual specialization. Am. Nat. 2003, 161, 1-28. [CrossRef]

35. Bolnick, D.I.; Ingram, T.; Stutz, W.E.; Snowberg, L.K.; Lau, O.L.; Paull, J.S. Ecological release from interspecific competition leads to decoupled changes in population and individual niche width. Proc. R. Soc. B Biol. Sci. 2010, 277, 1789-1797. [CrossRef]

36. Svanbäck, R.; Bolnick, D.I. Intraspecific competition drives increased resource use diversity within a natural population. Proc. R. Soc. B Biol. Sci. 2007, 274, 839-844. [CrossRef] [PubMed]

37. Araújo, M.S.; Martins, E.G.; Cruz, L.D.; Fernandes, F.R.; Linhares, A.X.; Dos Reis, S.F.; Guimarães, P.R. Nested diets: A novel pattern of individual-level resource use. Oikos 2010, 119, 81-88. [CrossRef]

38. Kohn, A.J.; Lloyd, M.C. Polychaetes of truncated reef limestone substrates on eastern Indian Ocean coral reefs: Diversity, abundance, and taxonomy. Int. Rev. Gesamten Hydrobiol. Hydrogr. 1973, 58, 369-400. [CrossRef]

39. Van Valen, L. Morphological variation and width of ecological niche. Am. Nat. 1965, 99, 377-390. [CrossRef]

40. Roughgarden, J. Evolution of niche width. Am. Nat. 1972, 106, 683-718. [CrossRef]

41. Levis, N.A.; Martin, R.A.; O'Donnell, K.A.; Pfennig, D.W. Intraspecific adaptive radiation: Competition, ecological opportunity, and phenotypic diversification within species. Evolution 2017, 71, 2496-2509. [CrossRef] [PubMed]

42. Phuong, M.A.; Mahardika, G.N. Targeted sequencing of venom genes from cone snail genomes improves understanding of conotoxin molecular evolution. Mol. Biol. Evol. 2018, 35, 1210-1224. [CrossRef]

43. Chang, D.; Olenzek, A.M.; Duda, T.F., Jr. Effects of geographical heterogeneity in species interactions on the evolution of venom genes. Proc. R. Soc. B Biol. Sci. 2015, 282, 20141984. [CrossRef]

44. Chang, D.; Duda, T.F., Jr. Age-related association of venom gene expression and diet of predatory gastropods. BMC Evol. Biol. 2016, 16, 27. [CrossRef] [PubMed]

45. Phuong, M.A.; Mahardika, G.N.; Alfaro, M.E. Dietary breadth is positively correlated with venom complexity in cone snails. BMC Genom. 2016, 17, 401. [CrossRef]

46. Romero, I.G.; Ruvinsky, I.; Gilad, Y. Comparative studies of gene expression and the evolution of gene regulation. Nat. Rev. Genet. 2012, 13, 505-516. [CrossRef]

47. Xu, Q.; Xing, S.; Zhu, C.; Liu, W.; Fan, Y.; Wang, Q.; Song, Z.; Yang, W.; Luo, F.; Shang, F.; et al. Population transcriptomics reveals a potentially positive role of expression diversity in adaptation. J. Integr. Plant Biol. 2015, 57, 284-299. [CrossRef] [PubMed]

48. Toews, D.P.L.; Campagna, L.; Taylor, S.A.; Balakrishnan, C.N.; Baldassarre, D.T.; Deane-Coe, P.E.; Harvey, M.G.; Hooper, D.M.; Irwin, D.E.; Judy, C.D.; et al. Genomic approaches to understanding population divergence and speciation in birds. Auk Ornithol. Adv. 2016, 133, 13-30. [CrossRef]

49. Herrmann, M.; Ravindran, S.P.; Schwenk, K.; Cordellier, M. Population transcriptomics in Daphnia: The role of thermal selection. Mol. Ecol. 2018, 27, 387-402. [CrossRef] [PubMed]

50. Duda, T.F., Jr.; Chang, D.; Lewis, B.D.; Lee, T. Geographic variation in venom allelic composition and diets of the widespread predatory marine gastropod Conus ebraeus. PLoS ONE 2009, 4, e6245. [CrossRef] [PubMed]

51. Palumbi, S.R. Nucleic acids II: The polymerase chain reaction. In Molecular Systematics; Sinauer \& Associates: Sunderland, MA, USA, 1996; pp. 205-247.

52. Rambaut, A. Se-Al: Sequence Alignment Editor; University of Oxford: Oxford, UK, 1996.

53. Tamura, K.; Peterson, D.; Peterson, N.; Stecher, G.; Nei, M.; Kumar, S. MEGA5: Molecular evolutionary genetics analysis using maximum likelihood, evolutionary distance, and maximum parsimony methods. Mol. Biol. Evol. 2011, 28, 2731-2739. [CrossRef] [PubMed]

54. Whittaker, R.H. A study of summer foliage insect communities in the Great Smoky Mountains. Ecol. Monogr. 1952, 22, 1-44. [CrossRef]

55. Shannon, C.E. A mathematical theory of communication. Bell Syst. Tech. J. 1948, 27, 379-423. [CrossRef]

56. FASTX-Toolkit. Available online: http://hannonlab.cshl.edu/fastx_toolkit/ (accessed on 2 June 2014).

57. MacManes, M.D. On the optimal trimming of high-throughput mRNA sequence data. Front. Genet. 2014, 5, 13. [CrossRef] 
58. Brown, C.T.; Howe, A.; Zhang, Q.; Pyrkosz, A.B.; Brom, T.H. A reference-free algorithm for computational normalization of shotgun sequencing data. ArXiv12034802 Q-Bio 2012. Available online: https://arxiv.org/ abs/1203.4802 (accessed on 2 June 2014).

59. Grabherr, M.G.; Haas, B.J.; Yassour, M.; Levin, J.Z.; Thompson, D.A.; Amit, I.; Adiconis, X.; Fan, L.; Raychowdhury, R.; Zeng, Q.; et al. Full-length transcriptome assembly from RNA-Seq data without a reference genome. Nat. Biotechnol. 2011, 29, 644-652. [CrossRef] [PubMed]

60. Kaas, Q.; Westermann, J.-C.; Halai, R.; Wang, C.K.L.; Craik, D.J. ConoServer, a database for conopeptide sequences and structures. Bioinformatics 2008, 24, 445-446. [CrossRef]

61. Langmead, B.; Trapnell, C.; Pop, M.; Salzberg, S.L. Ultrafast and memory-efficient alignment of short DNA sequences to the human genome. Genome Biol. 2009, 10, R25. [CrossRef] [PubMed]

62. Li, B.; Ruotti, V.; Stewart, R.M.; Thomson, J.A.; Dewey, C.N. RNA-Seq gene expression estimation with read mapping uncertainty. Bioinformatics 2010, 26, 493-500. [CrossRef]

63. Haas, B.J.; Papanicolaou, A.; Yassour, M.; Grabherr, M.; Blood, P.D.; Bowden, J.; Couger, M.B.; Eccles, D.; Li, B.; Lieber, M.; et al. De novo transcript sequence reconstruction from RNA-seq using the Trinity platform for reference generation and analysis. Nat. Protoc. 2013, 8, 1494-1512. [CrossRef]

64. Robinson, M.D.; Oshlack, A. A scaling normalization method for differential expression analysis of RNA-seq data. Genome Biol. 2010, 11, R25. [CrossRef]

65. Robinson, M.D.; McCarthy, D.J.; Smyth, G.K. edgeR: A Bioconductor package for differential expression analysis of digital gene expression data. Bioinformatics 2010, 26, 139-140. [CrossRef] [PubMed]

66. Langmead, B.; Salzberg, S.L. Fast gapped-read alignment with Bowtie 2. Nat. Methods 2012, 9, 357-359. [CrossRef] [PubMed]

67. Picard. Available online: http://broadinstitute.github.io/picard/ (accessed on 2 June 2014).

68. McKenna, A.; Hanna, M.; Banks, E.; Sivachenko, A.; Cibulskis, K.; Kernytsky, A.; Garimella, K.; Altshuler, D.; Gabriel, S.; Daly, M.; et al. The genome analysis toolkit: A MapReduce framework for analyzing next-generation DNA sequencing data. Genome Res. 2010, 20, 1297-1303. [CrossRef]

69. DePristo, M.A.; Banks, E.; Poplin, R.; Garimella, K.V.; Maguire, J.R.; Hartl, C.; Philippakis, A.A.; del Angel, G.; Rivas, M.A.; Hanna, M.; et al. A framework for variation discovery and genotyping using next-generation DNA sequencing data. Nat. Genet. 2011, 43, 491-498. [CrossRef]

70. Introduction to the GATK Best Practices. Available online: https://software.broadinstitute.org/gatk/bestpractices/ (accessed on 2 June 2014).

71. Patterson, N.; Price, A.L.; Reich, D. Population structure and eigenanalysis. PLoS Genet. 2006, 2, e190. [CrossRef] [PubMed]

72. Rousset, F. Genepop '007: A complete re-implementation of the genepop software for Windows and Linux. Mol. Ecol. Resour. 2008, 8, 103-106. [CrossRef] [PubMed]

(C) 2019 by the authors. Licensee MDPI, Basel, Switzerland. This article is an open access article distributed under the terms and conditions of the Creative Commons Attribution (CC BY) license (http://creativecommons.org/licenses/by/4.0/). 